\title{
APLICAÇÕES EDUCACIONAIS ATRAVÉS DO MAPA CONCEITUAL: INTEGRAÇÃO DAS DISCIPLINAS DO ENSINO MÉDIO COM O TEMA SEXUALIDADE
}

\author{
Suélly Lima dos Santos, Instituto Federal Fluminense-IFF Campus Campos Centro \\ suelsster@gmail.com \\ Marco Antonio Gomes Teixeira da Silva -IFF Campus Campos Centro \\ marcoagts@gmail.com \\ Suzana da Hora Macedo - IFF Campus Itaperuna \\ shmacedo@iff.edu.br
}

\section{Resumo}

A sexualidade é um dos pontos de discussões dentro do espaço educativo, pois percebe-se que a escola ainda não aborda esse tema de forma interdisciplinar. O papel da escola tem a função social de propagar o conhecimento formal e científico, principalmente quando é adotado em sala de aula, os professores buscam maneiras para minimizar o constrangimento por parte dos alunos. Diante alguns questionamentos dos discentes os professores encontram-se despreparados para lidar com o eixo em questão dentro da sala de aula e não sabem como agir frente a algumas manifestações. Assim este artigo pretende apresentar de que forma um dos eixos transversais, a sexualidade, vem sendo tratada no espaço educativo nas primeiras séries do ensino médio. A metodologia utilizada foi numa escola pública da cidade de Campos dos Goytacazes - RJ, aplicando o eixo transversal em todas as disciplinas do curso. $\mathrm{O}$ artigo tem como objetivo promover conscientização e participação efetiva do público-alvo, quanto às discussões a respeito da sexualidade e suas conseqüências em sala de aula. Como resultado deste trabalho a interdisciplinaridade se traduz, na prática de mapas conceituais, por um trabalho coletivo e solidário na organização da instituição de ensino e por outro lado as representações sociais.

Palavras-chave: Interdisciplinaridade, sexualidade, mapa conceitual, diversidade, eixo transversal.

\section{EDUCATIONAL APPLICATIONS THROUGH THE CONCEPT MAP: THE INTEGRATION OF HIGH SCHOOL SUBJECTS WITH SEXUAL THEME}

\begin{abstract}
Sexuality is one of the points of discussion within the education area, because it is perceived that the school still does not address this issue in an interdisciplinary way. The role of the school has the social function of spreading the formal and scientific knowledge, especially when it is adopted in the classroom, teachers seek ways to minimize the embarrassment on the part of students. Some questions before the students the teachers are unprepared to deal with the axis in question within the classroom and do not know how to react to some events. So this article aims to present how a transverse axis, sexuality is being treated in the educational space in the first year of high school. The methodology used was a public school in the city of Campos dos Goytacazes - RJ, applying the transverse axis in all disciplines of the course. The article aims to promote awareness and effective participation of the audience, as the discussions about sexuality and its consequences in the classroom. As a result of this interdisciplinary work is reflected in the practice of conceptual maps, for a collective work
\end{abstract}


and solidarity in the organization of the institution and on the other hand the social representations.

Key-words: Interdisciplinarity, sexuality, conceptual map, diversity, cross shaft.

\section{Introdução}

$\mathrm{O}$ artigo trata de um assunto tabu: a sexualidade e o tratamento desse assunto na escola. Aborda a falta de preparo de muitos professores para tratarem do assunto de forma natural e da solução encontrada na interdisciplinaridade para trabalhar esse tema. Isso leva para a construção de uma escola participativa e decisiva na formação do aluno. A ferramenta tecnológica que emprega mapa cognitivo apresenta-se atualmente dentro do novo contexto da educação. Logo, o recurso utilizado para agregar as disciplinas em torno do tema foi o mapa cognitivo no formato de Mapa Conceitual.

A questão da sexualidade envolve assuntos distintos, como: à importância do uso de métodos contraceptivos, suas indicações e contraindicações; as principais Doenças Sexualmente Transmissíveis (DST), suas formas de transmissão e prevenção; sobre aborto, mostrando quais são os principais métodos e quais os riscos para a saúde e por fim promover uma reflexão sobre gravidez na adolescência, seus riscos para saúde da adolescência e suas conseqüências.

Este tema transversal abarca desde conteúdos relativos ao comportamento sexual das pessoas e suas consequências até a diferença entre homens e mulheres na sociedade e no mercado de trabalho.

A escolha deste tema em estudo justifica-se porque é recorrente na vida escolar dos alunos, seja porque os mesmos estão sempre interessados, curiosos ou estão vivendo algo novo devido à transição de hormônios.

Para Silva e Braga (s.d.), a instituição é um lugar onde se deve disseminar o saber, não se deve esquecer a transgressão do conhecimento, uma vez que ocorrem mudanças na sociedade, como por exemplo, casos do tipo abuso sexual, gravidez precoce, dentre outros que precisam ser focados em sala de aula.

Dessa forma, há necessidade de trabalhar a temática da sexualidade dentro da escola, formando indivíduos capazes de saber discutir essas questões que fazem parte do cotidiano no espaço educativo, principalmente quando esses assuntos são de curiosidade dos adolescentes. Pois temas que têm tamanha relação com a vida, com o dia-a-dia, certamente aparecem nos momentos mais inesperados e os professores devem estar preparados para não desperdiçar ocasiões que muitas vezes são valiosos.

Biscoli et al. (2005) afirmam que:

A orientação da sexualidade nas escolas e, mais ainda, o preparo dos profissionais imbuídos nessa tarefa, principalmente dos professores que estão em maior contato com os alunos, torna-se essencial, quando se pensa no desenvolvimento integral do ser humano (Biscoli et al., 2005, p.47).

A aproximação acerca de como a escola e seus professores tem se ocupado com esta temática e quais os recursos e estratégias que utiliza ao abordar a questão da sexualidade e às vezes a de gênero nas atividades curriculares anuais (Riscarolli e Cirqueira, s.d.). 
As interconexões que acontecem nas disciplinas são causas e efeito da interdisciplinaridade. Nos programas de ensino é possível ter um eixo unificador, em torno do qual se organizam as disciplinas, tendo a participação de todas as cadeiras estruturando os seus próprios conteúdos, mas sempre voltado para o foco central. Permitindo permear por toda prática educativa.

Os temas transversais são debatidos em diferentes espaços sociais, em busca de soluções e de alternativas, confrontando posicionamentos diversos tanto em relação à intervenção no âmbito social mais amplo quanto à atuação pessoal. Estes temas envolvem um aprender a realidade, destinando-se a intervenção com o objetivo de transformação na sociedade.

A ação pedagógica através da interdisciplinaridade aponta para a construção de uma escola participativa e decisiva na formação do sujeito social. Tornando a experimentação da vivência de uma realidade global, que se insere nas experiências cotidianas do aluno, do professor e do povo e que, na teoria positivista era compartimentada e fragmentada.

Sujeitos a favorecer a criação de estratégias de organizações dos conhecimentos escolares em relação ao tratamento da informação, entre os diferentes conteúdos em torno de problemas ou hipóteses que facilitem aos alunos a construção de seus conhecimentos, a transformação da informação procedente dos diferentes saberes disciplinares em conhecimentos próprios.

A metodologia utilizada para trabalhar a interdisciplinaridade do tema "Sexualidade", é pautada nos conceitos do mapa conceitual onde relaciona-se as disciplinas envolvidas no tema.

Este artigo tem como objetivo promover uma conscientização e participação efetiva do público-alvo, quanto às discussões a respeito da sexualidade e suas consequiências em sala de aula.

\section{Interdisciplinarida de}

Alves et al. (2004) cita Japiassú (1976), à interdisciplinaridade faz-se mister a intercomunicação entre as disciplinas, de modo que resulte uma modificação entre elas, através de diálogo compreensível, uma vez que a simples troca de informações entre organizações disciplinares não constitui um método interdisciplinar.

A interdisciplinaridade trabalha com modos de conhecimentos que buscam reintegração de aspectos que ficam isolados uns dos outros pelo tratamento disciplinar. Com isso, busca uma visão ampla e adequada da realidade.

Para Carlos (s.d.) interdisciplinaridade é um ensino voltado para as questões social, política e econômica, permitindo a interação entre as disciplinas, possui cooperação e diálogo entre as disciplinas do conhecimento, mas se tratando de uma ação coordenada.

Refere-se de uma técnica que não dissolve as disciplinas no contexto escolar, mas que aumente o trabalho disciplinar na medida em que causa aproximação e articulação das atividades dos professores numa ação coordenada e orientada para objetivos bem definidos.

Essa modalidade de articulações dos conhecimentos escolares é uma forma de organizar a atividade de ensino e aprendizagem para compreensão de uma forma rígida, nem em função de algumas referências disciplinares preestabelecidas ou de uma homogeneização dos alunos.

A interdisciplinaridade só vale à pena se for uma maneira eficaz de atingir metas educacionais estabelecidas e compartilhadas pelos membros da unidade escolar. Somando as informações de diversas disciplinas. Para fins de associação das cadeiras, todas devem recorrer aos mesmos instrumentos de análise que seriam o denominador comum do tema 
transversal, propondo assim, a correção para a omissão do assunto em questão em uma escola dinâmica, participativa e decisiva.

Com a metodologia e o objetivo do presente artigo, pode-se aprofundar em diferentes parcelas, fazendo um trabalho de análise, onde este aprofundamento é rico e muitas das vezes necessário, mas é preciso ter consciência de que esta fazendo um recorte do objeto de estudo. A visão obtida é fragmentada.

O papel da interdisciplinaridade questiona essa segmentação dos diversos campos de conhecimento, por isso, buscam-se possíveis pontos de convergência entre as várias áreas e a sua abordagem conjunta, propiciando uma relação epistemológica entre as disciplinas (Garcia, s.d.).

\section{Mapas Conceituais}

Mapas conceituais estão muito ligados à teoria da aprendizagem significativa proposta por Ausubel. Porém, Ausubel nunca falou de mapas conceituais em sua teoria. Esta é uma técnica desenvolvida por Joseph Novak e seus colaboradores na Universidade de Cornell (EUA) (Moreira, 2010, p. 17). Portanto, os mapas conceituais foram desenvolvidos por Joseph Novak como ferramenta de característica construtivista para suporte à Aprendizagem Significativa de Ausubel. São diagramas usados para representar, descrever, estruturar, comunicar conceitos e as relações entre eles. Os conceitos constituem os nós do mapa e as relações são os links. Geralmente, os conceitos são substantivos e as relações são representadas por expressões verbais.

A Figura 1 ilustra o que é um mapa conceitual, incluindo a instalação do software e construção dos mapas.

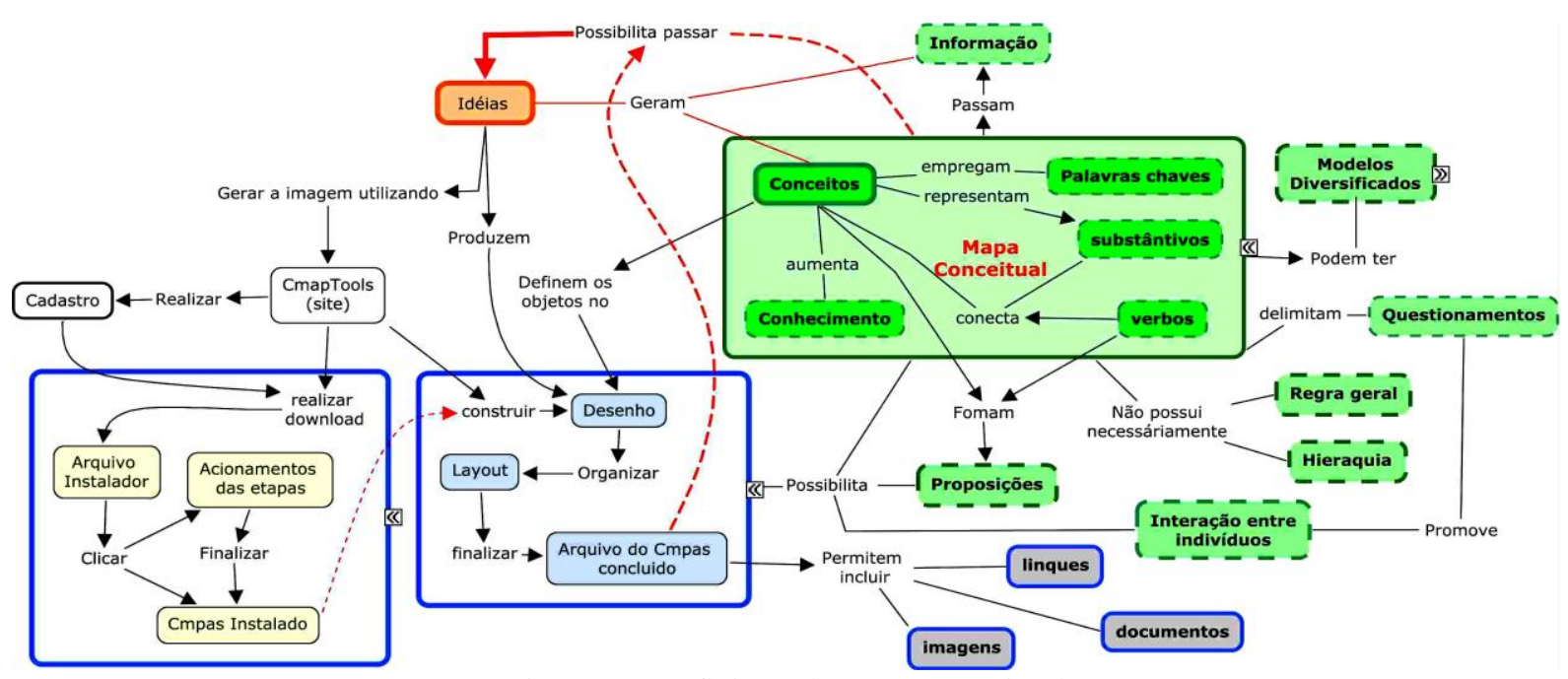

Figura 1 - Definição de mapa conceitual

Os mapas conceituais podem ser utilizados como instrumento de avaliação da aprendizagem, estratégia de estudo, apresentação de conteúdos, recurso de aprendizagem, entre outros. "Mapas conceituais podem ser utilizados na obtenção de evidências da aprendizagem significativa, ou seja, na avaliação da aprendizagem." (Moreira, 2010, p. 22). Porém é preciso ter cuidado, porque, assim como os mapas conceituais têm significados pessoais, alguns mapas são muito pobres e demonstram que não houve a compreensão do conteúdo desejado. "Os indícios da aprendizagem significativa serão verificados nos registros dos alunos por meio dos relatórios e principalmente, nos mapas conceituais construídos" (Carvalho et al, 2010). 


\section{Eixo transversal: sexualidade}

Dentre os seis eixos temáticos: ética, cultura, meio ambiente, saúde, sexualidade e trabalho o foco deste artigo será, sexualidade, e este será trabalhado por todos os professores que atuam nas primeiras séries do ensino médio. Cada um deles irá criar ações/projetos que permitem a utilização de várias frentes disciplinares.

Os eixos temáticos são temas sociais importantes que fazem uma instituição refletir nos seus contextos pedagógicos. Discutindo o sentido ético da convivência humana nas relações com várias dimensões da vida social, como por exemplo: ambiente, cultura, trabalho, consumo, sexualidade e saúde. Com isso a escola atua na educação de valores e atitudes em todas as áreas.

Discutir ou trabalhar este tema ou questões similares à sexualidade na escola, tem se constituído num grande desafio, primeiro porque a formação recebida pelos professores esta muito aquém dos anseios da geração que frequenta a escola; segundo porque a escola, em seu currículo, quando se propõe a realizar alguma atividade cujo objetivo é ampliar a reflexão sobre a sexualidade, cai no tradicional impasse de relacionar este tema com as questões pequenas de macho/fêmea (Riscarolli e Cirqueira, s.d.).

O tema em questão, como fenômeno educativo, implica não apenas num esforço de mudança pedagógica, mas, sobretudo cultural (Carvalho, 2005).

Assim, a questão da sexualidade no âmbito da escola ganha espaço, mas perde em profundidade já que nas poucas vezes quando se discuti sobre o tema isso é feito numa abordagem que não interessa ao público, muito embora aos alunos e professores defendam a importância dele como assunto pedagógico (Riscarolli e Cirqueira, s.d).

Biscoli et al. (2005) comentam que a sexualidade e suas manifestações, as dificuldades encontradas pelos professores e sua forma de lidar com as manifestações de sexualidade que ocorrem em sala de aula.

O corpo docente se encontra despreparados para lidar com a sexualidade em sala de aula e não sabem como agir frente a algumas manifestações sobre esse assunto com seus alunos. Ribeiro et al. (2004) dizem que as questões relativas à sexualidade devem limitar-se à privacidade de cada indivíd uo e de sua família.

Fazendo uso dos trabalhos com os eixos permite uma excelente oportunidade de experimentar o quanto faz bem a todos a partilha de saberes, pois aprender é dão gratificante como ensinar. Com essa nova metodologia de ensino, para que venha ter sucesso, é necessário ter o trabalho coletivo, respeitando as especialidades de cada área do conhecimento.

Para Biscoli et al. (2005) explanam que:

(...) a sexualidade sempre deverá ser pensada e questionada, tendo como referência o campo das relações sociais, cultura e das formas de vida, algo que é vivido no individual, mas é constituído e caracterizado pelos valores e normas do social, fugindo da discussão naturalizante (Biscoli et al., 2005, p. 49).

Numa perspectiva social, a orientação sexual, deverá ensinar ao aluno a respeitar a diversidade de comportamento relativo à sexualidade, deste que seja garantida a integridade e a dignidade do ser humano, respeitando os afetos dos próximos. 
A interdisciplinaridade permitiu um grande avanço na idéia de integração curricular, os interesses próprios de cada disciplina são preservados o que busca é a intercomunicação entre as cadeiras, tratando efetivamente de um único tema/objetivo comum.

Via de regra, a questão da sexualidade na escola e também na sociedade ganha relevância graças à ação dos movimentos sociais que estão acontecendo atualmente. De modo particular na escola, timidamente, se apresenta naquilo que se convencionou chamar de tema transversal.

Por fim a escola precisa estar integrada com os serviços públicos de saúde para o acompanhamento da condição de saúde dos alunos, assim como o seu desenvolvimento.

\section{Resultados}

Este experimento foi inicializado por uma docente que ministra a disciplina de Cidadania e Ética nas primeiras séries do ensino médio de uma escola pública localizada na cidade de Campos dos Goytacazes/RJ. Na ocasião utilizou-se a ferramenta CMap Tools que é gratuita e o seu download pode ser feito em: http://cmap.ihmc.us/download/.

Apesar do assunto, sexualidade, ser bastante mencionado, verifica-se que o corpo docente encontra-se despreparados para lidar com o eixo em questão dentro da sala de aula e não sabem como agir frente a algumas manifestações. Assim este artigo pretende apresentar de que forma um dos eixos transversais, a sexualidade, vem sendo tratada com essas novas tecnologias no espaço educativo.

A interdisciplinaridade de algum modo refere-se à espécie de interação entre as disciplinas ou áreas do saber (Carlos, s.d.).

Para Garcia (s.d.), convém salientar que é necessário um estudo conjunto, por parte da escola, para definir como cada disciplina irá tratar os temas transversais e verificar se estão suficientemente abordados. É preciso lembrar que cada um deles tem os seus próprios objetivos educacionais a serem atingidos, ou seja, não se trata apenas de comentar um tema, mas também de verificar se esta sendo contemplado ao longo do programa de ensino, assim pode-se prever o cumprimento dos objetivos.

Ribeiro et al. (2004) comentam que os professores utilizam uma das atividades, já citadas anteriormente, fazendo uso de uma situação para representar como a sexualidade é explanada em sala de aula.

Devido à extensão do tema, sua relação com as disciplinas pode acontecer em diversos âmbitos e para isso, serão utilizadas diferentes metodologias que estão dispostas na Figura 2. 


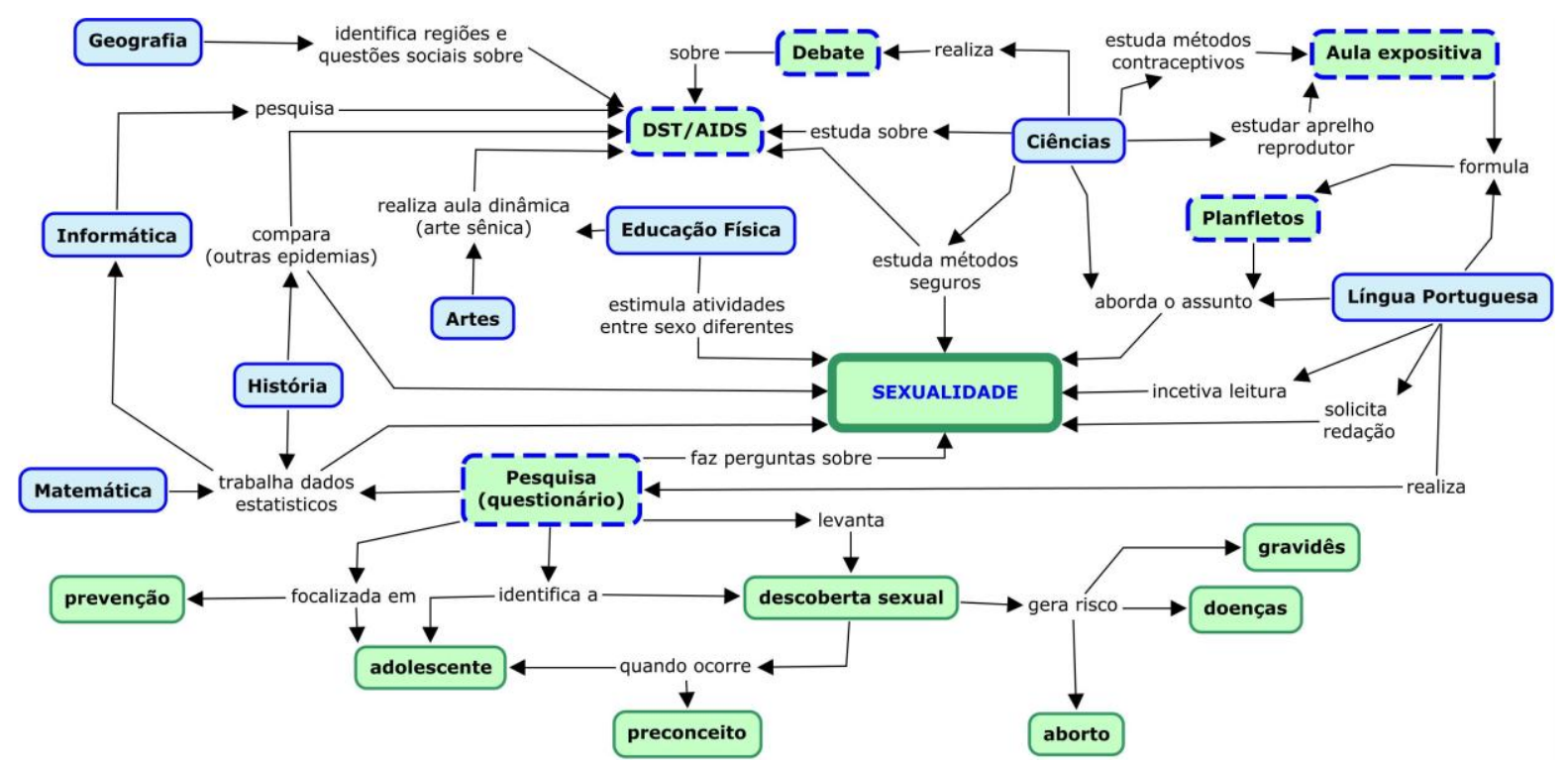

Figura 2 - Definição de mapa conceitual de interação entre as disciplinas

$\mathrm{Na}$ Figura 2, verifica-se que é possível fazer a conjunção de várias disciplinas por aglomeração, onde cada uma dá sua contribuição, mas preservando a autonomia e a integridade de seus métodos, de seus conceitos e por fim de suas epistemologias.

É nítido observar que os professores, de algumas disciplinas, se sentem mais confortáveis e mais preparados para estar trabalhando com o tema do artigo, como nas disciplinas que trata do corpo humano, é o caso de educação física e das ciências. Pode-se visto também que cada professor aborda a sexualidade de maneira diferenciada, uns refere-se ao coletivo, presente nas discussões.

Ainda se tratando das aplicabilidades do tema em questão, pode-se ser vista que a forma oralizada fornece uma troca de conhecimentos e ideias entre os grupos de jovens. Mas não ficando para trás a orientação escrita que tem sua parcela reservada com orientação de um professor, onde os alunos encontram novas informações e referenciais que abordam assuntos relacionados à sexualidade, importando por fim a leitura que servirá para ampliar seus horizontes.

Louro (1997) cita o modelo para a educação sexual feito nas escolas pela experiência com a leitura, uso de filmes, poesias, discussões interessantes que aguçam a imaginação e propiciem questões para refletir.

Porém, é fundamental que o debate esteja sempre presente para que os alunos criem condições de formar suas atitudes e opiniões.

No quadro 1 será visto as três fases das atividades, que servirá como novos campos científicos e dos conhecimentos disciplinares de maneira a gerar a compreensão da sensibilização do público-alvo, do aprofundamento do tema e da maximização dos conhecimentos.

\section{Quadro1 - Ações previstas}

\begin{tabular}{l|l} 
Fases & Atividades Pre vis tas
\end{tabular}




\begin{tabular}{|c|c|}
\hline Fases & Atividades Previstas \\
\hline $\begin{array}{l}\text { Sensibilização do } \\
\text { público-alvo }\end{array}$ & $\begin{array}{l}\text { - Reunião entre os representantes de turma e os professores para informar } \\
\text { e discutir as atividades previstas; } \\
\text { - Distribuições de panfletos informativos sobre as DST's abordam e } \\
\text { abuso sexual; } \\
\text { - Distribuição de preservativos; } \\
\text { - Palestra ministrada pelo docente e pelo órgão de saúde em sala de aula } \\
\text { abordando assuntos distintos relacionados à sexualidade; } \\
\text { - Exibição de vídeo Orientação sexual na Educação: Sexo, giz e } \\
\text { apagador (30 min) e outros; } \\
\text { - Realização de dinâmicas em sala de aula, favorecendo a assimilação } \\
\text { dos assuntos abordados; } \\
\text { - Ida às ruas ao redor do estabelecimento de ensino para preenchimento } \\
\text { das fichas de entrevista elaboradas na aula de Português; } \\
\text { - Palestra ministrada pelo docente em sala de aula abordando assuntos } \\
\text { distintos relacionados à sexualidade; } \\
\text { - Exibição de vídeo orientação sexual na Educação: Sexo, giz e apagador } \\
\text { (30 min) e outros; } \\
\text { - Sistematização dos dados levantados durante a entrevista e elaboração } \\
\text { de gráficos na aula de informática. }\end{array}$ \\
\hline $\begin{array}{l}\text { Aprofundamento } \\
\text { do tema }\end{array}$ & $\begin{array}{l}\text { - Pesquisa na internet sobre assuntos ligados ao tema definido pelos } \\
\text { docentes de Ciências, História e Geografia; } \\
\text { - Elaboração e exposição de cartazes nos corredores da escola. }\end{array}$ \\
\hline $\begin{array}{l}\text { Maximização dos } \\
\text { conhecimentos }\end{array}$ & $\begin{array}{l}\text { - Exibição de peça teatral com a participação dos alunos; } \\
\text { - Excursão para entidades filantrópicas para troca de experiências com } \\
\text { pessoas soropositivas; } \\
\text { - Realização de debate no pátio da escola entre os alunos, pais, } \\
\text { professores, pessoas soropositivas, adolescentes grávidas, profissionais } \\
\text { da área de saúde e outros, para consolidar as informações adquiridas } \\
\text { durante a execução do Projeto. }\end{array}$ \\
\hline
\end{tabular}

Fonte: autores

A metodologia do trabalho interdisciplinar implica na integração continua de conteúdos, apresenta a transmissão de uma concepção fragmentária para uma concepção unitária do conhecimento, tem o papel de superar a dicotomia entre ensino e pesquisa, considerando o estudo e a pesquisa, a partir de contribuição das diversas ciências e por fim o ensino-aprendizagem centrado numa visão de que se aprende ao longo de toda vida.

\section{Conclusões}

A integração entre os pais, a comunidade e o estabelecimento de ensino, torna-se fundamental para a formação consciente de todos envolvidos neste projeto, eliminando barreiras e preconceitos existentes em relação ao tema proposto deste artigo.

A partir daí, a escola deve ser considerada, pelos alunos, não só como um espaço de construção do conhecimento, mas também como um porto seguro. Pois o aluno não tem tempo e nem data para aprender o que significa que o mesmo aprende a toda hora e que não é apenas nos bancos escolares que terá um aprendizado amplo. Tento uma grande parcela dos acontecimentos do dia-a-dia do indivíduo.

Logo, os temas transversais não se devem constituir uma disciplina, mas permear toda a prática educativa, refletindo em um trabalho sistemático, contínuo, abrangente e integrado no 
decorrer de toda a educação. Seus objetivos e conteúdos devem estar inseridos em diferentes momentos de cada uma das disciplinas, sendo aplicados em uma e em outra de formas diferenciadas, mas sempre com o mesmo foco.

Conclui-se que os mapas conceituais se apresentaram como um ótimo recurso de ensino-aprendizagem, além de servir como uma ferramenta dinâmica para o processo ensinoaprendizado, permitindo a inserção de novos conceitos e conexões, caso seja preciso.

\section{Referências Bibliográficas}

ALVES, Railda F.; BRASILEIRO, Maria do Carmo E.; BRITO, Suerde M. de O. Interdisciplinaridade: um conceito em construção. Disponível em: $<$ http://www.ilea.ufrgs.br/episteme/portal/pdf/numero19/episteme19_artigo_alves_brasileiro_ brito.pdf> Acesso em 9 de agosto de 2011.

BISCOLI, Cristiane; FAVARÃO, Neide Rodrigues Lago; FEITEN, Raquel Helena; SOUZA, Andréia Caldas Pires; PERPÉTUO, Claudia Lopes. Sexualidade em sala de aula: um estudo da produção de sentidos. Revista Unipar. Arq. Ciênc. Saúde Unipar, Umuarama, v.9, jan./mar., 2005. Disponível em: <http://revistas.unipar.br/saude/article/viewFile/219/193.> Acesso em 5 de agosto de 2011.

CARLOS, Jairo Gonçalves. Interdisciplina ridade: o que é isso? Disponível em $<$ http://vsites.unb.br/ppgec/dissertacoes/proposicoes/proposicao_jairocarlos.pdf >Acesso em 5 de agosto de 2011.

CARVALHO, Sumaya Persona. Sexualidade, educação e cultura: instantâneos de escolas de Cuiabá e Várzea Grande. Cuiabá. 2005. Disponível em:

<http://www.ufmt.br/revista/arquivo/rev9/sexualidade.html> Acesso em 8 de agosto de 2011.

A. S.; BARONE, D. A. C.; ZARO, M. A. A aprendizagem significativa no ensino de engenharia de controle de automação. RENOTE. Revista Novas Tecnologias na Educação. V. 8 N³ 3, dezembro, 2010.

DUTRA, Ítalo Modesto; JOHANN, Stéfano Pupe. Por uma abordagem construtivista dos mapas conceituais. Disponível em:

$<$ http://mapasconceituais.cap.ufrgs.br/acai/ambiente/atividades/ativ_33/10:08:54_03-08-

2006_117_mapasconstrutivismo.pdf> Acesso em: 10 de outubro de 2011.

GARCIA, Lenise Aparecida Martins. Transversalidade e Interdisciplinaridade. Disponível em: <http://4pilares. net/text-cont/garcia-transversalidade-print.htm > Acesso em 5 de agosto de 2011.

LOURO, Guacira Lopes. Gênero, sexualidade e Educação: uma perspectiva pósestruturalista.1.ed. São Paulo:Vozes, 1997.

MOREIRA, M. A. Mapas Conceituais e Aprendizagem Significativa São Paulo: Centauro, 2010.

RIBEIRO, Paula Regina Costa; SOUZA, Nádia Geisa Silveira de; SOUZA, Diego Onofre. Sexualidade na sala de aula: pedagogias escolares de professoras das séries inicias do Ensino Fundamental. Revista Estudos Feministas. Rev. Estud. 
Fem. vol.12 no .1. Florianópolis. Jan./Apr. 2004.

Disponível

em: $<$ http://www.scielo.br/scielo.php?pid=S0104-026X2004000100006\&script=sci_arttext $>$ Acesso em 5 de agosto de 2011.

RISCAROLLI, Eliseu; CIRQUEIRA, Karlene Borges. Sexualidade e gênero nas escolas do Bico do Papagaio. Disponível em <http://www.fazendogenero.ufsc.br/7/artigos/R/RiscarolliCirqueira_07_B.pdf > Acesso em 5 de agosto de 2011.

SILVA, Solange Mendonça da; BRAGA, Eliane Rose Maio. Formação docente: mídia e a sexualidade. Disponível em: <http://alb.com.br/arquivo-morto/portal/5seminario/ PDFs_titulos/formacao_docente_midia_e_a_sexualidade.pdf > Acesso em 8 de agosto de 2011. 